\title{
RADIODIAGNOSTIC EXAMINATION OF THE SWIMBLADDER OF SOME FISH SPECIES
}

\author{
A. BEREGI ${ }^{1 *}$, CS. SZÉKELY ${ }^{3}$, L. BÉKÉSI $^{2}$, Judit SZABÓ $^{1}$, V. MOLNÁR ${ }^{1}$ and K. MOLNÁR ${ }^{3}$ \\ ${ }^{1}$ Department and Clinic of Internal Medicine and ${ }^{2}$ Department of Parasitology and \\ Zoology, Faculty of Veterinary Science, Szent István University, Budapest, H-1400, \\ P.O. Box 2, Hungary; ${ }^{3}$ Veterinary Medical Research Institute, Hungarian Academy \\ of Sciences, Budapest, Hungary
}

(Received March 16, 2000; accepted October 30, 2000)

\begin{abstract}
Radiodiagnostic methods have not been used previously for studying the anatomy and diseases of the swimbladder of freshwater fish species. In this study, the radiographic anatomy of the swimbladder and species-related differences in swimbladder structure were studied on plain radiographs taken of 12 Hungarian fish species of major economic importance. Changes observed by radiography were also studied by conventional parasitological methods. The radiodiagnostic method reported here appears to be a useful complement to diagnostic examinations that have been based merely on dissection so far. It enables evaluation of the pathological lesions in live condition, without causing damage to the fish.
\end{abstract}

Key words: Swimbladder, radiodiagnosis, swimbladder changes

In pisciculture, radiography has already been used by several authors for studying anatomical relationships (Smith and Smith, 1994) and for determining the damage caused by parasites (Treasurer, 1992). Elema et al. (1994) applied radiology for studying the effective concentration of flumequine in Atlantic salmon (Salmo salar L.), Horsberg et al. (1996) used it in pharmacokinetic e xperiments while Nagelkerke and Sibbing (1996) in fish nutrition studies. Love and Lewbart (1997) employed radiographic techniques for the detection of di fferent pathological changes of ornamental fish, while Wells and Cowan (1982) used such methods for demonstrating the toxic effects exerted by chem icals.

From the available literature it appears that radiodiagnostic methods have not yet been used for studying the swimbladder of commercial freshwater fish species, apart from a single study on the swimbladder of eels (Beregi et al., 1998). In this work, plain radiographs were taken of Hungarian fish species of the greatest economic importance in order to reveal differences in their swi mbladder structure. The method is based on the radiodiagnostic principle that o rgans filled with air are radiotransparent and thus readily discernible as dark areas on the radiograph (negative contrast).

*E-mail: aberegi@ns.univet.hu; Fax: +36 (1) 478-4137 
BEREGI et al.

\section{Materials and methods}

Fish indigenous in Hungary were used in this study. The fish were co llected by permission of the competent authorities, with electrofishery devices from Lake Balaton, from the Kis-Balaton water reservoir, and from fish farms. The fish were subjected to radiological examination in live condition. A total of 239 specimens of 19 fish species were examined.

The number of examined specimens of the different species was as fo 1lows: common carp [Cyprinus carpio (L.)] 167 specimens, European eel (Anguilla anguilla L.) 45 specimens, sterlet (Acipenser ruthenus L.) 2 specimens, pike (Esox lucius L.) 2 specimens, asp [Aspius aspius (L.)] 2 specimens, barb [Barbus barbus (L.)] 2 specimens, bream [Abramis brama (L.)] 2 specimens, crucian carp [Carassius carassius (L.)] 2 specimens, gibel carp [Carassius auratus gibelio (Bloch)] 2 specimens, bighead (Aristichthys nobilis Richardson) 2 specimens, sheatfish (Silurus glanis L.) 2 specimens, pikeperch [Stizostedion lucioperca (L.)] 2 specimens, Volga pikeperch [Stizostedion volgense (Gmelin)] 2 specimens. One specimen each of the following other fish species was also e $\mathrm{x}$ amined: roach [Rutilus rutilus (L.)], pumpkinseed [Lepomis gibbosus (L.)], perch (Perca fluviatilis L.), brown bullhead (Ictalurus nebulosus LeSueur), rudd [Scardinius erythrophthalmus (L.)], bleak [Alburnus alburnus (L.)], river goby (Neogobius fluviatilis Pall.). In view of the minor economic importance of these latter fish, their radiographs are not evaluated here.

A TUR DE 38 type mobile X-ray apparatus (Germany) was used, with the following parameters: tube voltage $50-100 \mathrm{kV}$, electronic time switch 0.04 to $8 \mathrm{mAs}$. The radiographs were taken on $18 \times 24$ size Kodak T-MAT S/RA X-ray film. While in other species of animals the exposure values are selected on the basis of the layer thickness of the body part to be examined, in this case the e xposure values were set in proportion to the body mass due to the similar body shape of different fish species.

The fish were placed directly onto the cassette which was covered with polyethylene foil for protection. Two-way radiographs were taken in all cases, in laterolateral (LL) and in dorsoventral (DV) view. After radiography, the fish were identified individually on the basis of body length and body mass.

Eels were restrained manually by holding them within a towel, while for dorsoventral radiographs fish having a laterally flattened body were supported with a paper towel from the side.

After radiography and interpretation of the radiographs, the eel and co mmon carp specimens were euthanised by an overdose of anaesthetic, and the swimbladder changes were studied also by conventional paras itological methods. 


\section{Results}

The healthy swimbladder is clearly outlined on the radiographs. The swimbladder gives a homogeneous radiographic shadow under the spinal column despite the fact that the shadow of the ribs is projected onto it. Its size is propo $\mathrm{r}$ tional to the body size of the fish.

In addition to the swimbladder, the bony skeleton consisting of vertebrae, ribs, fin rays and cranial bones is also well distinguishable on radiographs. The bony skeleton of fish of smaller body size and of cartilaginous fish is not ou tlined sharply because of its lower calcium content. In addition to the swimbla dder and the bony elements, occasionally the gas-filled gut and the pneumatic duct also give a radiographic shadow.

The radiographs were evaluated as follows, with emphasis on the radi ographic structure, shape and dimensions of the swimbladder:

Sterlet (A. ruthenus): the cartilaginous skeleton is clearly outlined but the spinal column is only slightly visible; therefore, the vertebrae were not counted. In the caudal part of the first body half a non-divided, longitudinally oval swi mbladder of slightly rounded caudal end can be seen (Fig. 1). In ventral view it is well visible that the swimbladder is dorsoventrally flattened (Fig. 2).
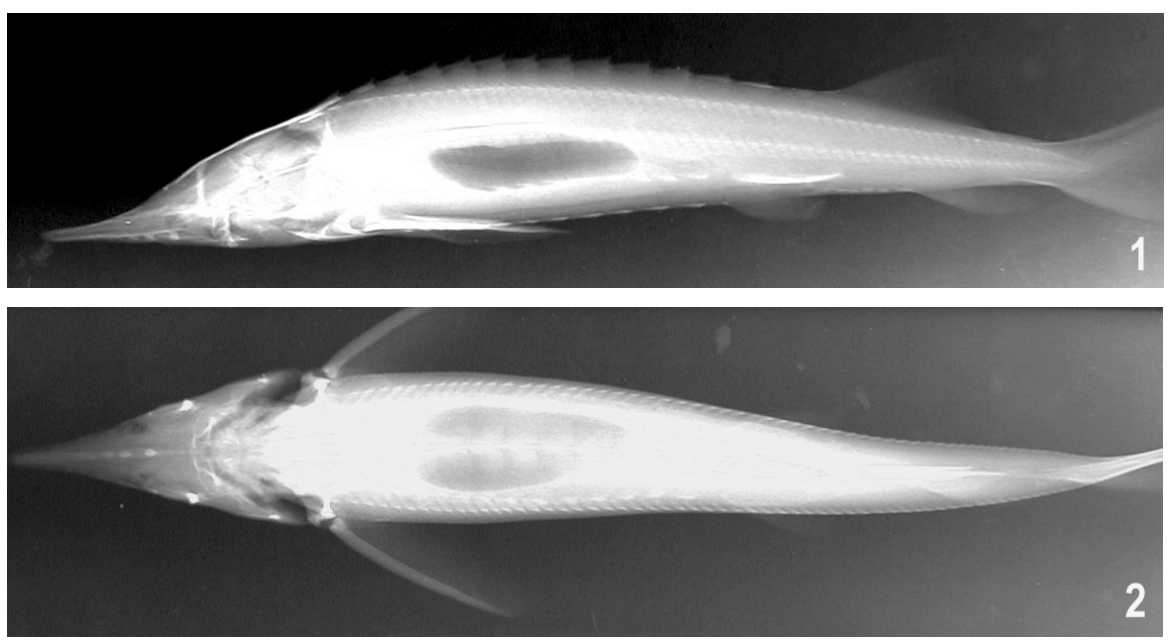

Fig. 1. Radiograph of a sterlet with its elongated one-sac swimbladder in lateral view. $\times 0.3$

Fig. 2. Radiograph of a sterlet with its dorsoventrally flattened swimbladder in ventral view. The lighter contour of the spinal column seemingly divides the sac into two parts. $\times 0.3$

Eel (A. anguilla): the single swimbladder, which is divided into two parts in the median line by the rete mirabile, occupies 15 intervertebral spaces. Its cr anial end is thicker and round, while its caudal end is na rrower (Figs 3 and 4). 

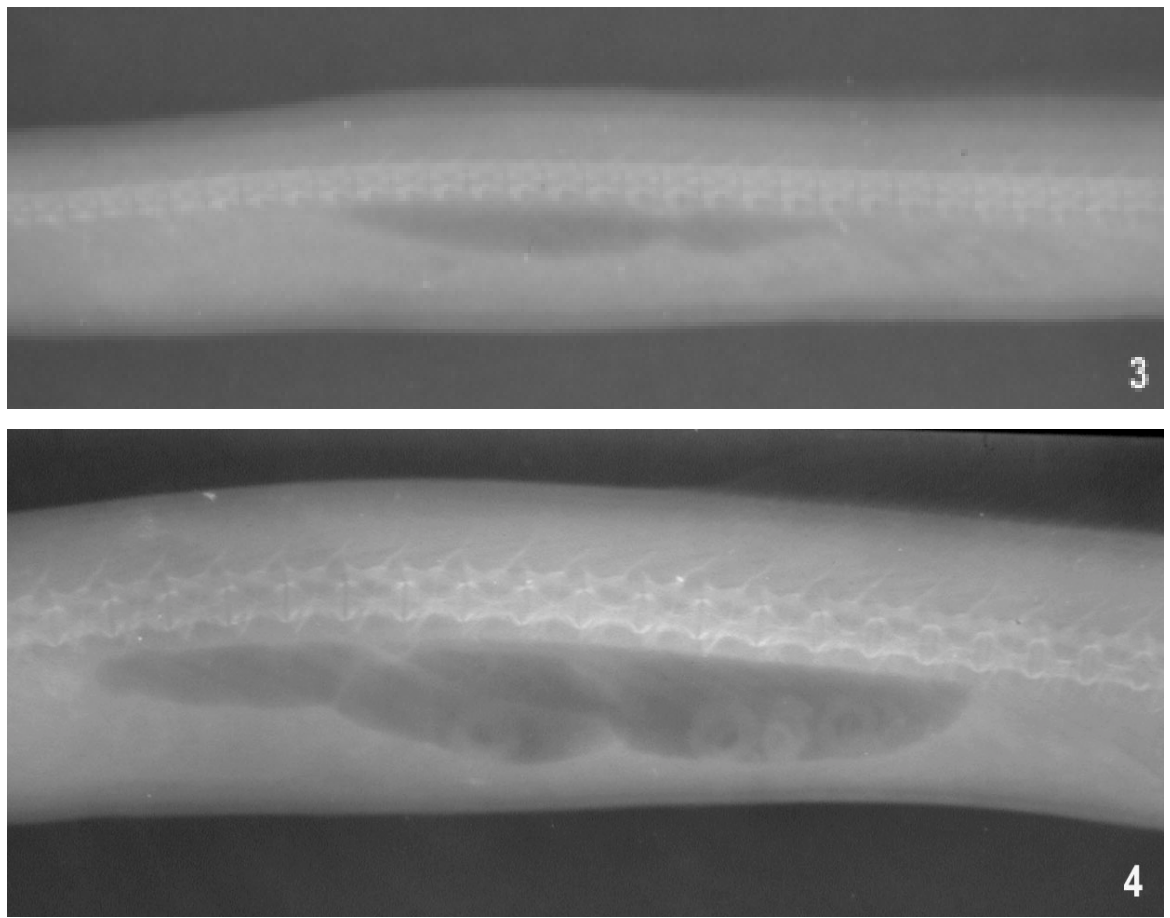

Fig. 3. Radiograph of a healthy European eel with its swimbladder. $\times 1.2$

Fig. 4. Radiograph of an eel infected by Anguillicola crassus. In addition to the two worm-filled chambers of the swimbladder the highly dilated pneumatic duct is seen. $\times 0.8$

Barbel (B. barbus): the double swimbladder occupies 22 intervertebral spaces. The caudal sac is narrower and longer than the cranial one; its caudal end is tapering (Figs 5 and 6).

Bream (A. brama): the double swimbladder occupies 18 intervertebral spaces, the cranial sac is spherical while the caudal one is wider, longer and bends downward (Fig. 7).

Crucian carp (C. carassius): the double swimbladder occupies 17 intervertebral spaces. The cranial sac is spherical and narrower than the caudal one. The caudal sac is elongated oval and its caudal end narrows (Fig. 8).

Gibel carp (C. auratus gibelio): the swimbladder is similar to, but more elongated than, that of the crucian carp (Fig. 9).

Common carp (C. carpio): the double swimbladder occupies 18 interve rtebral spaces. The cranial sac is bigger, while the caudal sac tapers and bends downward at its caudal end (Figs 10-12).

Bighead (A. nobilis): the double swimbladder occupies 19 intervertebral spaces. The cranial sac is bigger and slightly tapering at its end. The caudal sac has a tapering end and an arched ventral edge (Fig. 13). 

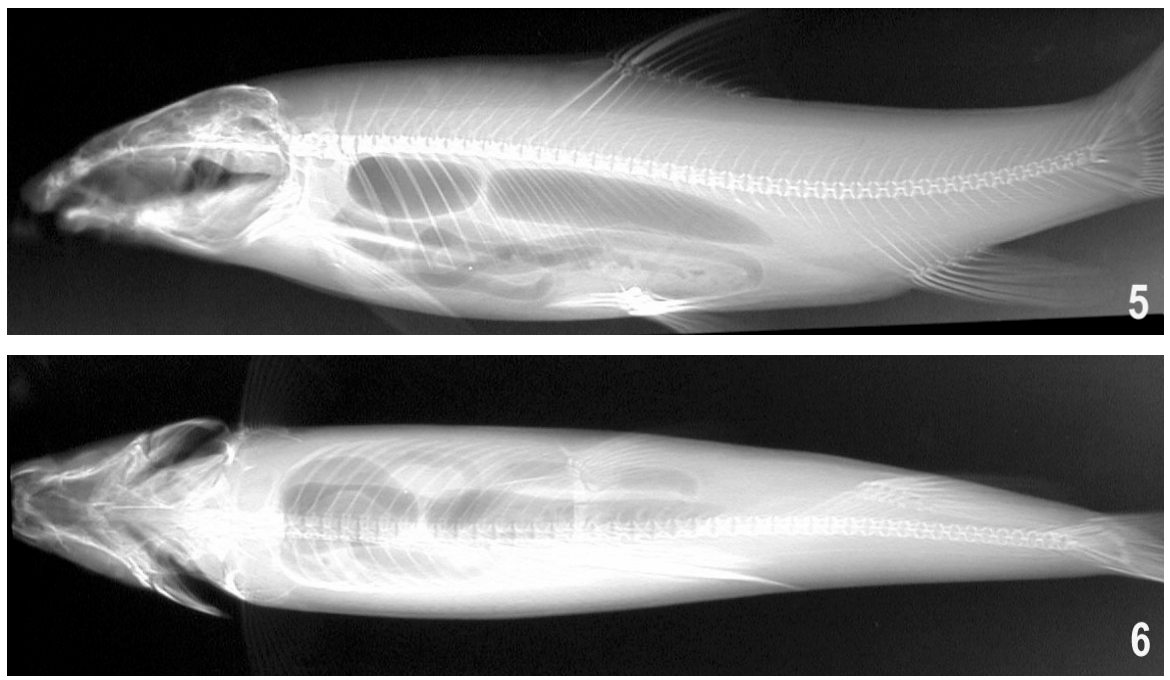

Fig. 5. Radiograph of a barbel in lateral view. $\times 0.3$

Fig. 6. Radiograph of a barbel in ventral view. The double swimbladder is partially covered by the gas-filled intestine. $\times 0.3$

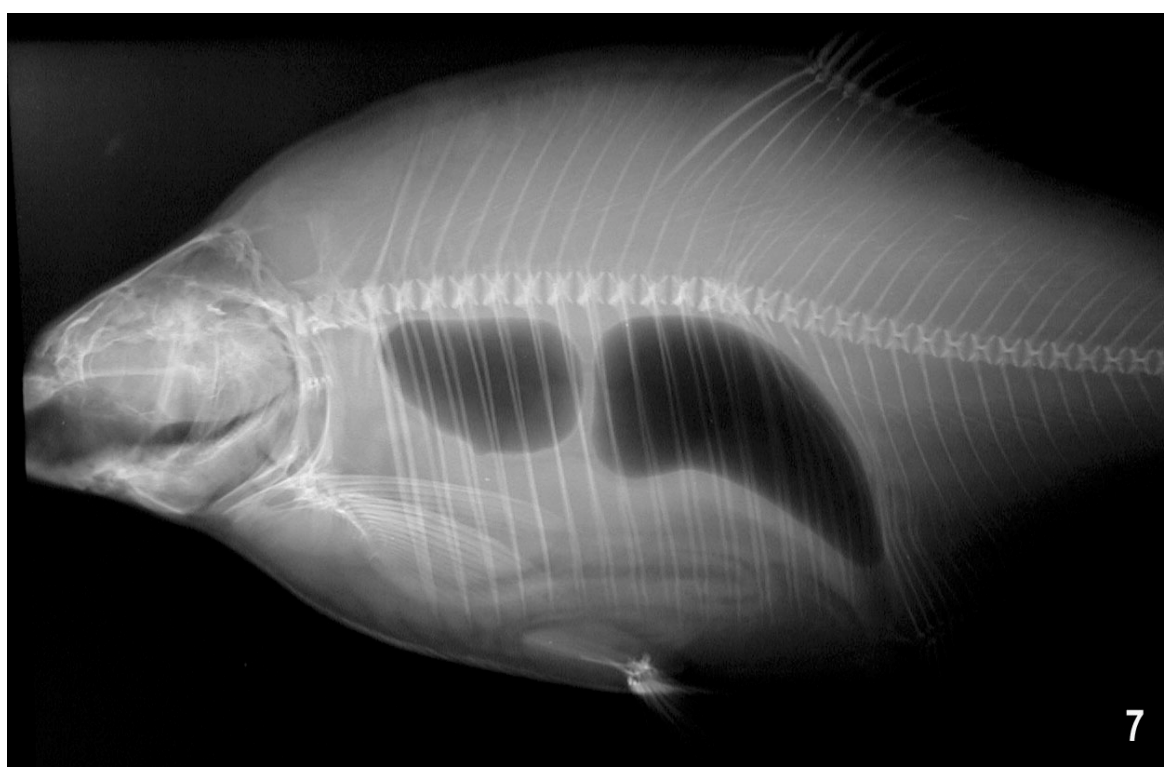

Fig. 7. Radiograph of a bream in lateral view. The second sac of the double swimbladder is larger. $\times 0.4$ 


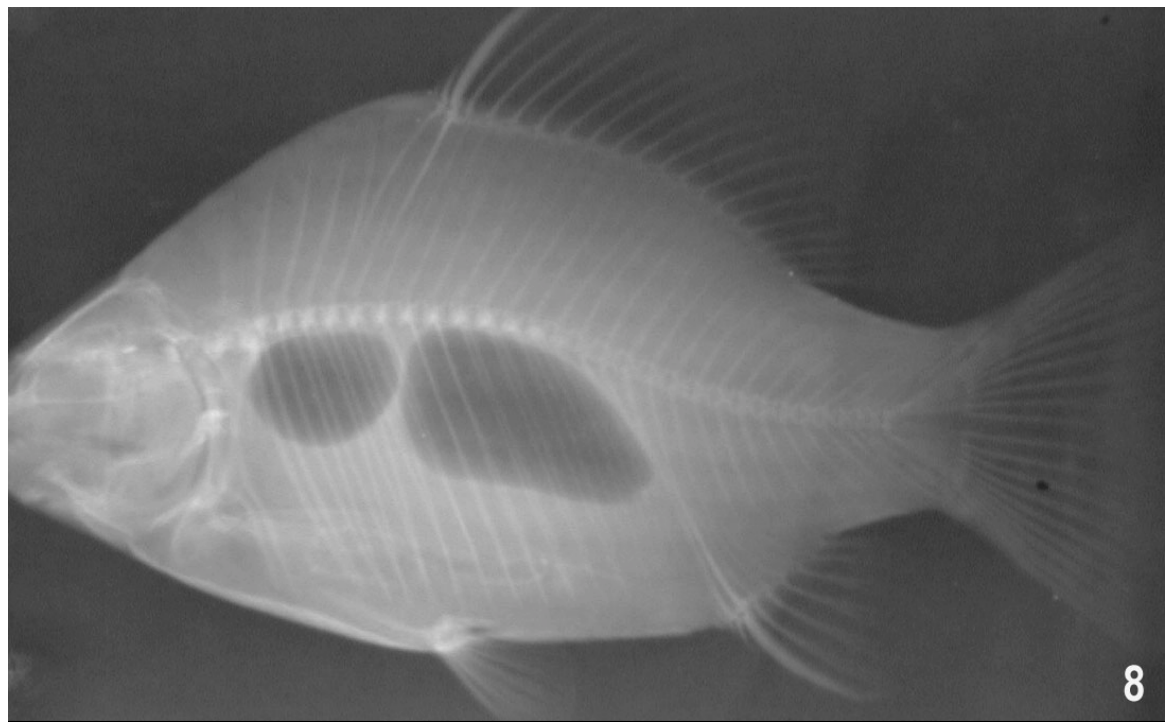

Fig. 8. Radiograph of a crucian carp in lateral view. The second sac is larger. $\times 0.7$

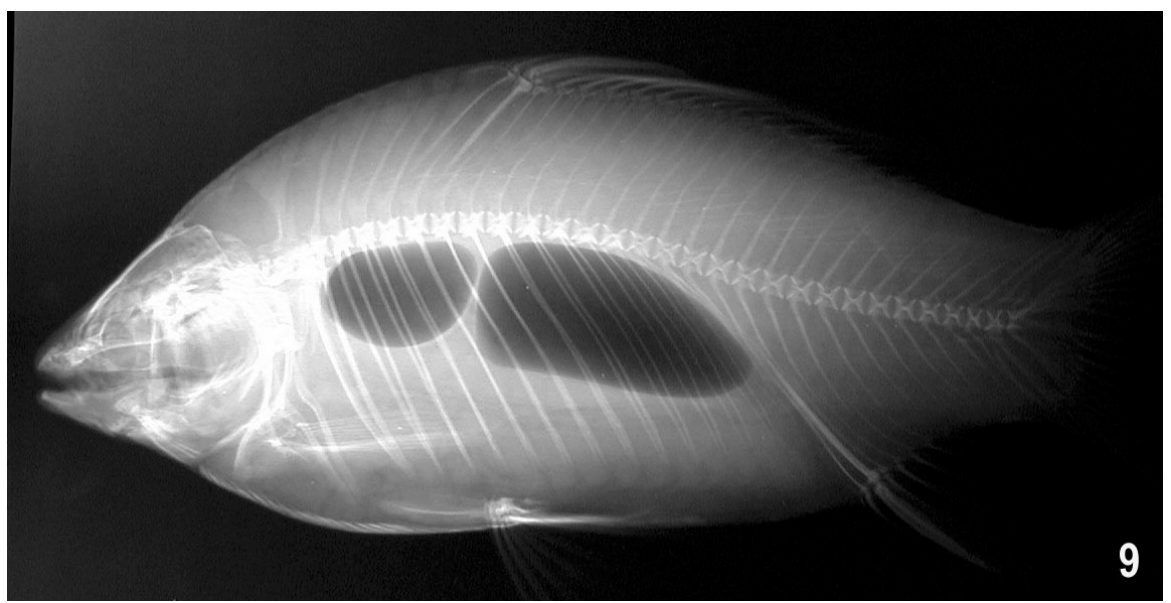

Fig. 9. Radiograph of a gibel carp in lateral view. The second sac is larger. $\times 0.4$

Asp (A. aspius): The double swimbladder occupies 24 intervertebral spaces. The cranial sac is oval and tapering at its end. The caudal sac is bigger and wider, longer and bends downward (Fig. 14).

Sheatfish (S. glanis): the single swimbladder occupies 16 intervertebral spaces and is of uniform width in its entire length (Fig. 15). In ventral view it is well visible that the swimbladder is dorsoventrally flattened (Fig. 16). 

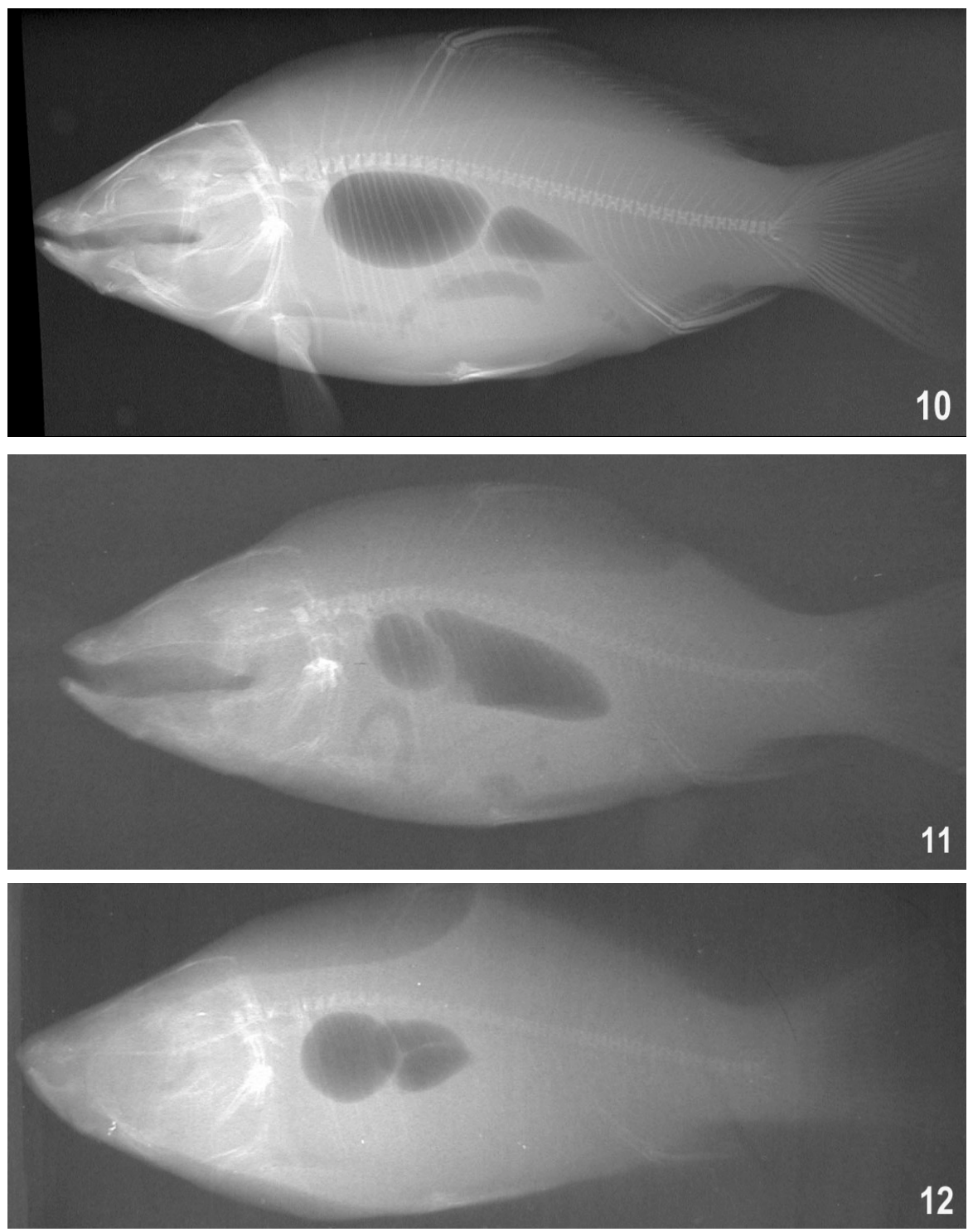

Fig. 10. Radiograph of a healthy common carp. The anterior sac of the swimbladder is significantly larger than the posterior one. $\times 0.5$

Fig. 11. Radiograph of a common carp affected by swimbladder inflammation. The anterior chamber of the swimbladder is reduced while the posterior chamber is severely dilated. $\times 1.2$

Fig. 12. Radiograph of a common carp in a severe stage of swimbladder inflammation. Due to thickening of the swimbladder wall the gas volume of both chambers is drastically reduced. $\times 0.9$

Pikeperch (S. lucioperca): the single swimbladder occupies 20 intervert ebral spaces and its caudal end is markedly wider (Fig. 17). 


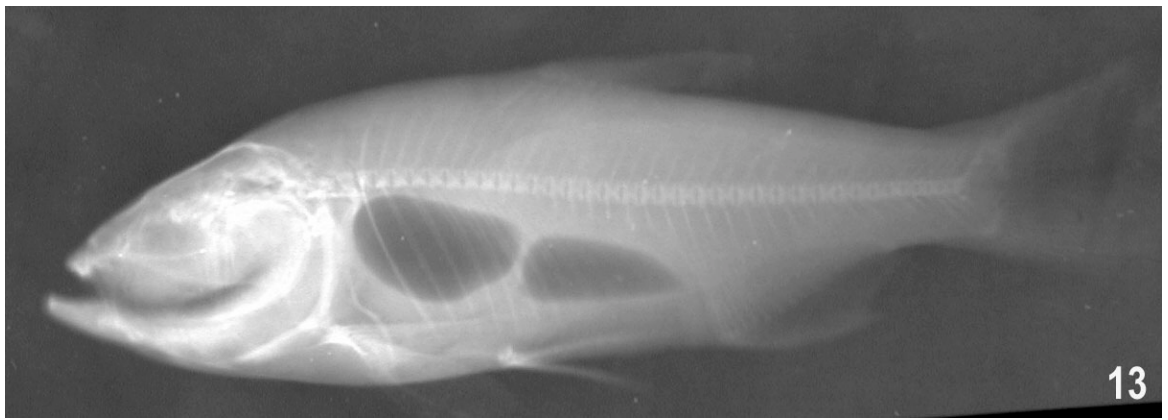

Fig. 13. Radiograph of the bighead in lateral view. The anterior chamber is larger than the posterior one. $\times 0.6$

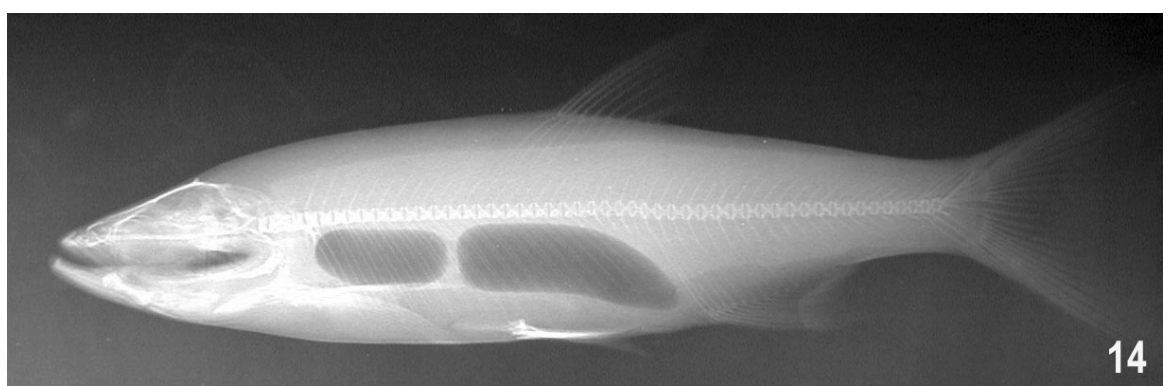

Fig. 14. Radiograph of an asp in lateral view. The posterior chamber is larger than the anterior one. $\times 0.4$

Volga pikeperch ( $S$. volgense): the single swimbladder occupies 19 interve rtebral spaces, its cranial end is narrower while its caudal end is rounded (Fig. 18).

Pike (E. lucius): the narrow, longitudinally elongated swimbladder occ upies 38 intervertebral spaces. Caudal to its second third, the swimbladder b ecomes narrower and bends downward (Fig. 19).

The swimbladder of about 20 out of the 45 eel specimens examined had a radiographic structure different from normal. By analysis of the radiographs, the swimbladder lesions were divided into the following five severity grades ( Beregi et al., 1998): Grade 1: healthy swimbladder (Fig. 3), the shape of the swimbladder is clearly outlined; grade 2: mild swimbladder lesion, the radiographic shadow of the swimbladder is inhomogeneous; grade 3: pronounced swimbladder lesion, the $\mathrm{r}$ adiographic shadow of the swimbladder is deformed (Fig. 4); grade 4: severe changes, the swimbladder is indicated only by a narrowed, occasionally spot-like radiographic shadow representing the air contained by the bladder; grade 5: very severe change; no air content can be detected in the swi mbladder.

The swimbladder of 43 out of the 165 common carp specimens examined had a radiographic structure deviating from that typical of the healthy organ. These fish were affected by parasitic swimbladder inflammation. By analysis of the $\mathrm{r}$ a- 
diographs, 3 out of the 5 severity grades described for the eel could be found in the common carp. Grade 1: healthy swimbladder, the shape of the swimbladder is clearly outlined (Fig. 10). Grade 2: mild swimbladder lesion, the radiographic shadow of the swimbladder is inhomogeneous, the second sac is enormously $\mathrm{d}$ ilated, while the first sac is reduced in volume. Dissection of the fish revealed thickening of the wall of the anterior chamber and hyperaemic inflammation in the posterior chamber (Fig. 11). Grade 3: pronounced swimbladder lesion, the radi ographic shadow of the swimbladder indicated that the lumen of both chambers was narrowed. At dissection of the fish the wall of the chambers was severely thic kened while their lumen was shrunken and partially filled with fluid (Fig. 12).
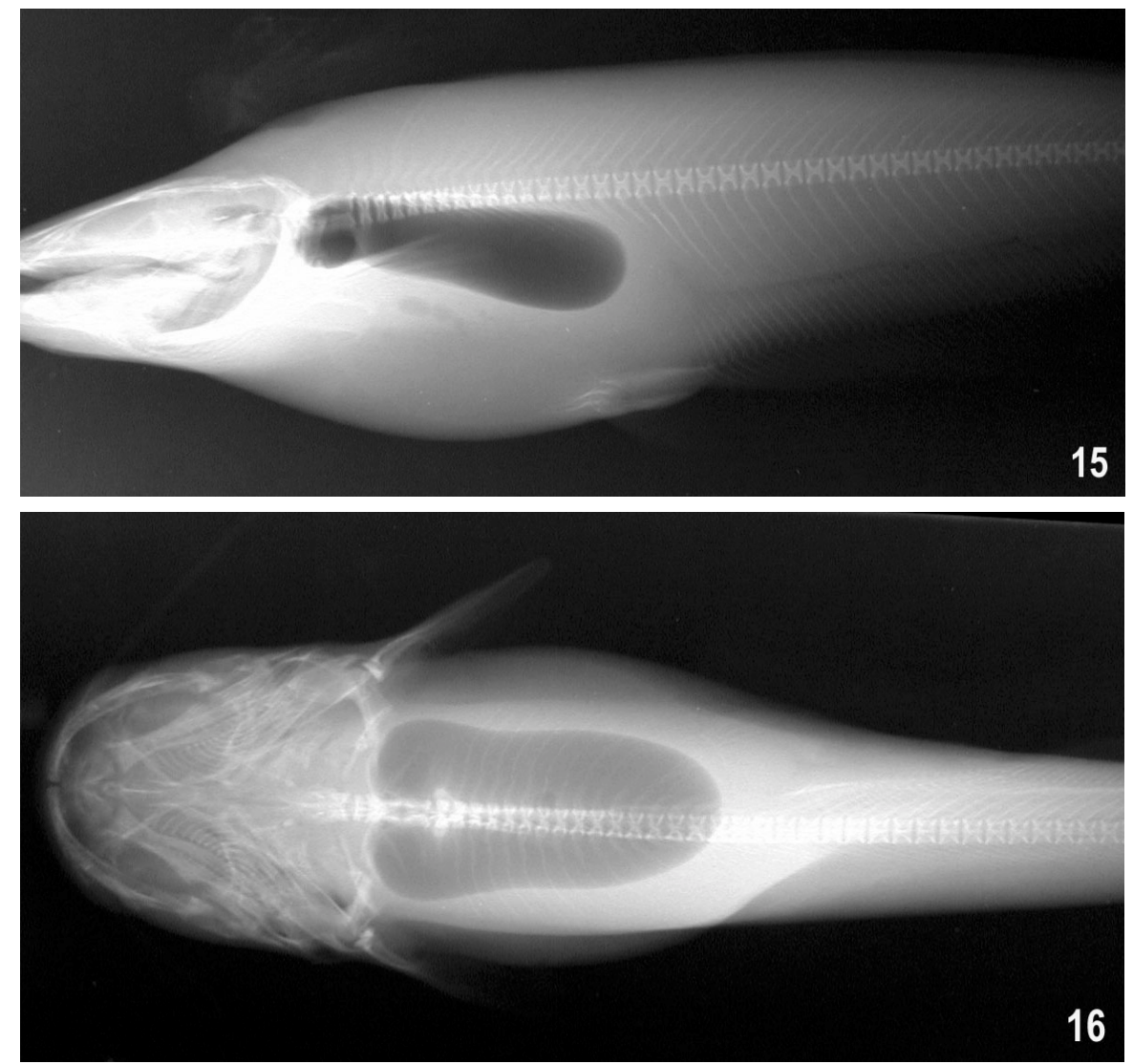

Fig. 15. Radiograph of a sheatfish in lateral view. The swimbladder is located in the anterior part of the body. $\times 0.5$

Fig. 16. Radiograph of a sheatfish in ventral view. In this view it is well visible that the swimbladder of this species is dorsoventrally flattened. $\times 0.5$ 

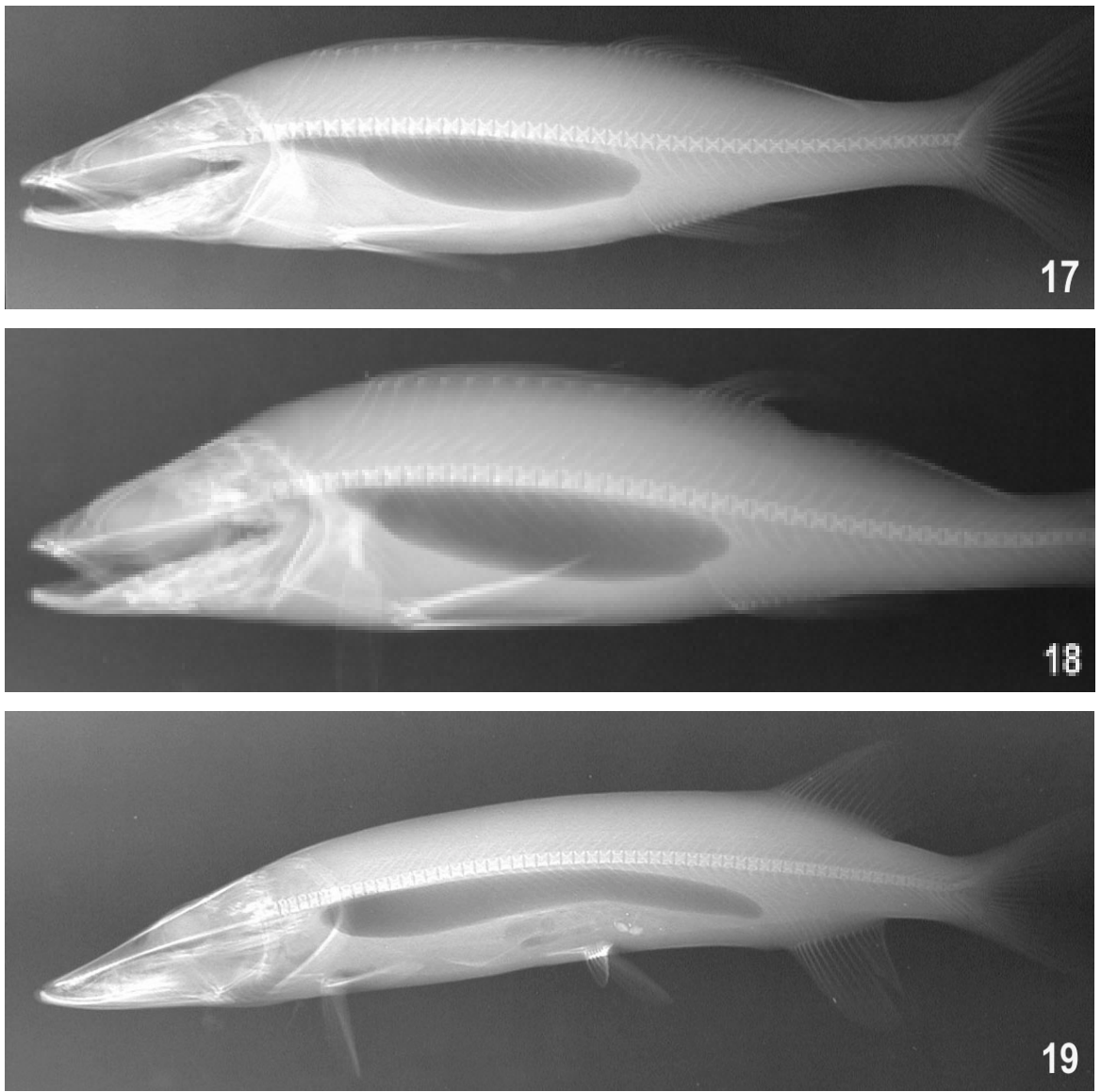

Fig. 17. Radiograph of a pikeperch. The one-chamber swimbladder is caudally widened. $\times 0.4$ Fig. 18. Radiograph of a Volga pikeperch. The one-chamber swimbladder is caudally widened. $\times 0.5$

Fig. 19. Radiograph of a pike. The one-chamber swimbladder is an elongated sac. $\times 0.4$

Knowledge of the radiographic structure of the swimbladder of other fish species renders it possible to identify swimbladder lesions in affected fish spec imens and to study the aetiology of such changes.

When comparing the results of dissections with those of radiography, it was found that in eels the swimbladder changes observed by radiography were caused by the nematode Anguillicola crassus Kuwahara, Niimi et Itagaki (Beregi et al., 1998). In common carp, the swimbladder lesions were due to the myx osporean parasite Sphaerospora renicola Dykova and Lom which had not been studied by radiological methods previously. 


\section{Discussion}

The swimbladder is an essential organ of fish, a hydrostatic organ that keeps fish afloat by modifying their specific gravity. Air-filled structures, such as the swimbladder (and occasionally the pneumatic duct and the gut), are clearly ou tlined on radiographs. X-ray examinations performed during this study show that species-related differences in swimbladder structure are well recognisable by rad iography. Using this method the anatomical characteristics and apparent changes of different fishes could be well documented. The results obtained by this method conformed to the findings of fish dissections and proved the following. The swimbladder of cyprinids is divided into two communicating parts by strangulation, and is connected with the gut by the pneumatic duct. The pike has a one-chamber swimbladder which is also connected with the gut. The one-chamber swimbladder of sheatfish is connected with the gut and with the labyrinthine organ. On the other hand, the one-chamber swimbladder of sterlet and pikeperch is closed without ducts.

Evaluating the positioning of fish for radiographic examination, it was found that radiographs of dorsoventral view provided less information on the status of the inner organs and the swimbladder, as on that view the shadows of the spinal column and the inner organs were projected onto each other (Figs 2, 6 and 16).

The lateral position gave more information on the status of the swimbla dder, but in infected eels the dilated pneumatic duct while in barbel the gas-filled gut disturbed the evaluation.

Swimbladder inflammation, especially that caused by parasites, has long been known in some economically important fish species ( Csaba et al., 1984). Radiographs provide information primarily on the shape of the swimbladder and on the amount of air contained by it; however, the outlines of nematodes present in the swimbladder are also well visible (Beregi et al., 1998).

Following interpretation of the radiographs it can be stated that radiology is a life-sparing method which is highly suitable for studying swimbladder changes and is a useful complement to diagnostic investigations that have been based solely on fish dissections so far. Infection of the swimbladder and the severity of its pathological lesions can be judged safely in live fish, without causing damage to the fish examined. The efficacy of therapeutic interventions can also be monitored and confirmed by this technique.

\section{Acknowledgements}

The authors thank the Hungarian Scientific Research Fund (OTKA project No. 031755), the staff of the Balaton Fisheries Company, the crew of the research boat of the Balaton Limnological Research Institute of the Hungarian Academy of Sciences, TEHAG (Warm-water Fish Hatchery), Hortobágy Fisheries Company for the test materials. Financial support to this work was mostly provided by the Fisheries Fund of the Hungarian Ministry of Agriculture. 


\section{References}

Beregi, A., Molnár, K., Békési, L. and Székely, Cs. (1998): Radiodiagnostic method for studying swimbladder inflammation caused by Anguillicola crassus (Nematoda: Dracunculoidea). Dis. Aquat. Org. 34, 155-160.

Csaba, Gy., Kovács-Gayer, É., Békési, L., Bucsek, M., Szakolczai, J. and Molnár, K.(1984): Studies into the possible protozoan aetiology of swimbladder inflammation in the carp fry. J. Fish Dis. 7, 235-239.

Elema, M. O., Hoff, K. A. and Kristensen, H. G. (1994): Multiple-dose pharmacokinetic study of flumequine in Atlantic salmon (Salmo salar). Aquaculture 128, 1-11.

Horsberg, T. E., Hoff, K. A. and Nordmo, R. (1996): Pharmacokinetics of florfenicol and its metabolite florfenicol amine in Atlantic salmon. J. Aquat. Anim. Health 8, 292-301.

Love, N. E. and Lewbart, G. A. (1997): Pet fish radiography: technique and case history reports. Vet. Radiol. Ultrasound 38, 24-29.

Nagelkerke, L. A. J. and Sibbing, F. A. (1996): Efficiency of feeding on zebra mussel (Dreisena polymorpha) by common bream (Abramis brama), white bream (Blicca bjoerkna), and roach (Rutilus rutilus): the effects of morphology and behavior. Can. J. Fish. Aquat. Sci. 53, 2847-2861.

Smith, S. A. and Smith, B. J. (1994): Xeroradiographic and radiographic anatomy of the channel catfish (Ictalurus punctatus). Vet. Radiol. Ultrasound 35, 384-389.

Treasurer, J. (1992): Vertebral anomalies associated with Myxobolus sp. in perch (Perca fluviatilis) in a Scottish loch. Bull. Eur. Assoc. Fish Pathol. 12, 61-63.

Wells, D. E. and Cowan, A. A. (1982): Vertebral dysplasia in salmonids caused by the herbicide trifluralin. Environ. Pollut. 29, 249-260. 